\title{
Value of Modified Duran's Test in Clinical Diagnosis of Carpal Tunnel Syndrome
}

\author{
Mahdi K. Qadir*, Samih K. Hasan Kalwuri \\ Department of Physiotherapy, Erbil Health Technical College, Erbil Polytechnic University, Erbil, Kurdistan Region, Iraq
}

\begin{abstract}
${ }^{*}$ Corresponding author: Mahdi K. Qadir, Department of Physiotherapy, Erbil

Health Technical College, Erbil Polytechnic University, Erbil, Kurdistan Region, Iraq. E-mail: mahidqader@epu. edu.iq
\end{abstract}

Received: 15 January 2020 Accepted: 05 May 2020

Published: 30 June 2021

DOI

10.25156/ptj.v11n1y2021.pp1-6

\section{A B S T R A C T}

Background: Carpal tunnel syndrome (CTS) is a medical condition, the most common, most important, and best defined, and the most carefully studied of all nerve entrapment syndromes. Objective: Our study aims to evaluate clinical tests in the diagnosis of CTS with special reference to modified Duran's test regarding specificity and sensitivity. Patients and Methods: A prospective study carried out on 300 hands in 240 patients with symptomatic CTS was taken, from August 2015 to February 2017, at Erbil Teaching hospital (Orthopedic department). History, clinical examination, and Electrophysiological by Electromyography and Nerve conduction study and 250 persons without symptoms on 300 hands were taken as a controlling group. We applied the five clinical provocative tests on each group, Phalen's test, Tinal's test, original Duran's test, arm Tourniquet test, and Reversed Phalen's test. In this research, we compared former tests by our test modification (Duran's test), considering specificity, accuracy, and sensitivity. Results: Findings show that the modified Duran's test was the most specific (94\%), accurate (94\%), and sensitive (94\%) in comparison with the other provocative tests. The modified Duran test had the highest positivity rate, according to the cases in less than 1-month history of symptoms it reached: $81.8 \%$ which was higher than the result of the previous tests in comparison to the previous clinical tests. Its mean time was $11.5 \mathrm{~s}$. Conclusions: Modified Duran's test was simple, noninvasive, most sensitive, and most specific in comparison to other clinical tests. Furthermore, the reaction time of Modified Duran's test was the shortest,

Keywords: Carpal tunnel syndrome; Diagnosis; Provoking test

\section{INTRODUCTION}

Carpal tunnel syndrome (CTS) is a hand and wrist condition. It is the most important, most common of all entrapment nerve syndromes (Douglas et al., 1981). In most cases can be diagnosed only by clinical history and physical examination (Trumble et al., 2002; Parisdm, 2005). More than $80 \%$ of the patients are over the age of 40 years and women are more affected than men, $50 \%$ of the cases are bilateral and the dominant hand is usually affected first and severely involved (De-La-Llave-Rincón et al., 2012). It is defining as a compressive neuropathy of the median nerve where it passes through the carpal tunnel which is created by the transverse carpal ligament and carpal bones, producing paresthesia and pain in the median nerve distribution in the hand.

These are described as causal factors: Endocrinology, infection, rheumatologic, trauma, tumoral lesions, and pregnancy or may be idiopathic (Wanitwattanarumlug and Varavithya, 2012).

CTS is mainly diagnosed on a clinical basis, and the diagnosis is made after careful history and examination, including known provocative tests of varying effectiveness and reliability. (Douglas et al., 1981) Provocative tests have a very important role in the diagnosis of CTS especially in early cases (Kuschner, 1999) which includes the Phalen's test, Tinel's test, Arm sphygmomanometer test, and Duran's carpal compression test.

CTS can result from ischemia and mechanical compression of the median nerve. In Duran's carpal compression testtransient reversible ischemia of the median nerve is induced by direct pressure on an already ischemic nerve by high pressure within the carpal tunnel and acute conduction block (Durkan, 1991). In Phalen's wrist flexion test-the size of the carpal tunnel is reduced which compresses the median nerve more than it was already compressed in the neutral position. In Tinel's percussion test-median nerve conduction is blocked by sharp tapping upon the nerve (Phalen, 1972; Gellman et al., 1986). Ischemic nerve becomes more sensitive to the tapping in its ischemic part. Finally, in Arm sphygmomanometer test-venous congestion is induced in the hand, wrist, and forearm which reduces the size of the carpal tunnel and compresses the median nerve (Boland and Adams, 1999).

Electrodiagnostic studies are used to confirm the diagnosis and some studies discourage its use as an exclusive tool, (Louis and Hankin, 1987) but other studies had refined 
the technique and data analysis to establish a dependable and reliable diagnosis (Werner and Andary, 2011). Over recent years, the use of ultrasonography, to demonstrate the usefulness of this method as an aid to diagnosing CTS, in cases which compatible symptoms are present together with normal physical and electroneurography examination result (Kang et al., 2012; Rahmani et al., 2011).

\section{The Aim of the Study}

The aim of the study was to evaluate the modified Duran's test in the clinical diagnosis of CTS and compared it to the other valuable clinical test.

\section{PATIENTS AND METHODS}

240 patients (300 hands) were studied prospectively in a certain period (from August 2015 to February 2017), at Erbil Teaching hospital. All the patients had symptoms of CTS and have definite abnormalities of electromyography (EMG) and nerve conduction study (NCS). This group of patients was considered as the positive group, among these 240 patients, 216 were female, and 24 were male (female/ male ratio are 9/1). The symptom in 132 patients was on their right hands, and in 28 patients was on their left hand. While in 80 patients, it was found bilateral. The ages of the patient were ranged between 26 and 54years (the average was 39 years old).

One hundred and seventy patients were housewives, 35 typists, 30 clerical workers, and five dentists. CTS was suspected by a history of pain and paresthesia in the median nerve distribution of the hand. The hand was tested electrophysiologically by EMG and NCS and by positive findings that have CTS by positive findings. The criteria for abnormal EMG can be identified when the distal motor nerve conduction velocity over the carpal tunnel is more than $4.5 \mathrm{~ms}$, or $1 \mathrm{~ms}$ more than ulnar nerve on the same side or the opposite (asymptomatic) median nerve side in unilateral cases, while for abnormal NCS when the sensory velocity is more than $3.5 \mathrm{~ms}$ or is $1 \mathrm{~ms}$ more than ulnar nerve on the same side or the opposite (asymptomatic) median nerve side in a unilateral case.

The control group was 250 patients (300) hands. None of them had any history and symptom of CTS, and as a negative group, they consisted of 200 female and 50 males (female/male ratio are 4/1). Among them, 160 were righthanded patients, 50 of them are bilateral, and 40 only left-handed. The range of their ages was 28 to 60 years (average age 40 years).

The clinical tests were carried out on the two groups as follows: a. Original Duran's test

It consists of a device that is created by a link of an aneroid pressure manometer in a rubber atomizer-bulb from a sphygmomanometer producing direct pressure on the median nerve under the flexor retinaculum by a pressure of (150) $\mathrm{mmHg}$ during $30 \mathrm{~s}$. A timer recorded the interval from the application of compression to the onset of symptoms in the median nerve distribution on the hand

b. Modified Duran's test

Consists of a frim plastic board $(7 \times 11 \mathrm{~cm})$ with central round edge rectangular pieces $(3 \mathrm{~cm} \times 6 \mathrm{~cm})$ which is enough to cover the volar aspect of an adult wrist and apply pressure upon the median nerve running under the flexor retinaculum. This board was incorporated into a blood pressure cuff. Linked to a manometer from a mercurial sphygmomanometer is shown in [Figure 1]. A pressure of $150 \mathrm{mmHg}$ was applied for $30 \mathrm{~s}$. The timer reported the interval from compression applied to the onset of symptoms in the hand's median nerve distribution.
c. Phalen's test
d. Tinal's test
e. Reversed Phalen's test
f. Tourniquet test.

\section{Statistical Analysis}

Data were translated into the codes by employing a particularly coding sheet and then the data transformed into computerized data. Statistical analyses SPSS version 23 (Statistical Package for the Social Science) which is a computer software were used to analyze the data.

The significance of statistically analyzed data in the different groups in a mean of the confirm finding variable in quantitative method (like pressure needed to achieve a positive test) between two groups was estimated by $t$-test. The statistical importance of the association among two

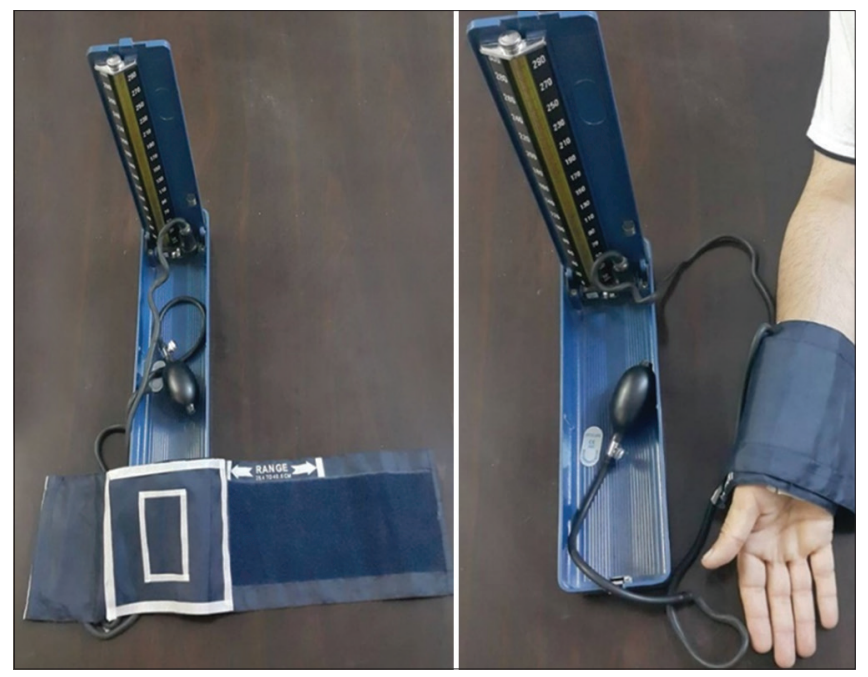

Figure 1: Modified Duran's a device 
variables groups (like duration of symptoms and positivity rate of the test) was evaluated by the Chi-square test. $P<0.05$ level of significance was estimated as statistically important.

Test performance characteristics (Sorlie, 1995). The performance characteristics of a test or criteria, sometimes called test operating characteristics include, among others: Specificity, sensitivity, negative predictive value, and positive predictive value the used formulas in the calculation are:

$$
\begin{gathered}
\text { Sensitivity }=\frac{\text { No.of true positives }}{\text { No.of diseased person }} \\
\text { Specificity }=\frac{\text { No.of true negatives }}{\text { No. of non }- \text { diseased person }} \\
\text { PPV }=\frac{\text { No. of true positives }}{\text { No. of positive test results }} \\
\text { NPV }=\frac{\text { No. of true negatives }}{\text { No. of negative test results }} \\
\text { Accuracy }=\frac{\text { No. of }(\text { true positives }+ \text { true negatives })}{\text { Total No. }}
\end{gathered}
$$

\section{RESULTS}

The results of the clinical tests for the diseased positive group (300 hands) are as follows:

\section{Modified Duran's Test}

It was positive in 282 hands (94\%) with a mean time of $11.5 \mathrm{~s}$ from the application of the pressure to the onset of symptoms (range 9-19s). The pressure which was applied to induce symptoms is $150 \mathrm{mmHg}$ for patients with normal blood pressure and $165 \mathrm{mmHg}$ (range $160-180 \mathrm{mmHg}$ ) for hypertensive patients with mean systolic blood pressure (160 mmHg) (range 150-180 mmHg) and mean diastolic blood pressure (102 $\mathrm{mmHg}$ ) (range $95-110 \mathrm{mmHg}$ ).

\section{Original Duran's Test}

It was positive in 258 hands $(86 \%)$ with a mean time of $23.5 \mathrm{~s}$ (range $17-30 \mathrm{~s}$ ). The pressure which was applied to include CTS symptoms is $150 \mathrm{mmHg}$ for patients with normal blood pressure and $180 \mathrm{mmHg}$ range 165-190 mmHg for hypertensive patients with mean arterial systolic blood pressure $160 \mathrm{mmHg}$ and mean diastolic blood pressure (103 $\mathrm{mmHg})$.

\section{Phalen's Test}

Two hundred and thirty-six hands were positive $(78.7 \%)$ with a mean time of $44.7 \mathrm{~s}$ (range 33-60 s).

\section{Reversed Phalen's Test}

It was positive in 225 hands $(75 \%)$ with a mean time of $47.2 \mathrm{~s}$ (range 32-60 s).

\section{Tinel's Test}

It was positive in 209 hands (69.7\%). In 159 hands (53\%), the Tourniquet test was positive.

The results of 300 hands clinical tests are shown in the control group as shown in Table 1.

\section{Original Duran's Test}

It was positive in 19 hands $(6.3 \%)$ with a mean time of 24 s (range 19-28 s).

\section{Modified Duran's Test}

It was positive in 18 hands $(6 \%)$ with a mean time of $20 \mathrm{~s}$ (range 13-28 s).

\section{Phalen's Test}

It was positive in 48 hands (16\%) with a mean time of $40 \mathrm{~s}$ (range 35-60 s).

\section{Reversed Phalen's Test}

It was positive in 53 hands $(17.7 \%)$ with a mean time of $44.5 \mathrm{~s}$ (range 39-60 s).

\section{Tinel's Test}

It was positive in 36 hands (12\%).

\section{Tourniquet Test}

It was positive in 69 hands $(23 \%)$.

The sensitivity, specificity, positive predictive value, negative predictive value and accuracy of Modified Duran's test, Duran's test, and other tests were the highest specificity was from Modified Duran's test which was $94 \%$, its sensitivity was $94 \%$, its positive predictive value was $94 \%$, and its negative predictive value was $94 \%$, and was $94 \%$ with the result of others tests is shown in Table 2.

Modified Duran's test was positive in cases with a short duration of history $<1$ month with an $80 \%$ positivity rate; which increases with the duration of symptoms reaching as high as $97 \%$ in more than 6 months' duration of symptoms. This means that modified Duran's test remains higher in its positivity rates than other tests along with all the duration of symptoms, this was statistically significant in Chi-square $P=0.02$ [Table 3]. 
Table 1: The cases-control difference in means of certain criteria

\begin{tabular}{|c|c|c|c|c|c|c|c|}
\hline \multirow[t]{2}{*}{ ??? } & \multicolumn{2}{|c|}{ Number } & \multicolumn{2}{|c|}{ Mean } & \multicolumn{2}{|c|}{ SD (Standard Deviation) } & \multirow[t]{2}{*}{$P(t$-test) } \\
\hline & Positive & Negative & Positive & Negative & Positive & Negative & \\
\hline Pressure needed to have positive Duran's test & 258 & 19 & 160 & 150 & 10.37 & 0 & 0.003 \\
\hline Pressure needed to have positive Modified Duran's test & 282 & 18 & 158 & 150 & 9.11 & 0 & 0.002 \\
\hline $\begin{array}{l}\text { Time Interval (Seconds) Needed to have a positive Duran's } \\
\text { test }\end{array}$ & 258 & 19 & 23.5 & 24 & 3.91 & 2.80 & 0.02 \\
\hline $\begin{array}{l}\text { Time Interval (Seconds) Needed to have a positive } \\
\text { Modified Duran's test }\end{array}$ & 282 & 18 & 11.5 & 20 & 2.65 & 4.70 & $<0.001$ \\
\hline $\begin{array}{l}\text { Time Interval (Seconds) Needed to have a positive } \\
\text { Phalen's test }\end{array}$ & 236 & 48 & 44.70 & 47.00 & 8.38 & 8.06 & 0.008 \\
\hline $\begin{array}{l}\text { Time Interval (Seconds) Needed to have a positive } \\
\text { Reversed Phalen's test }\end{array}$ & 225 & 53 & 47.2 & 44.5 & 8.74 & 5.50 & 0.03 \\
\hline
\end{tabular}

Table 2: Validity parameters (sensitivity and specificity, positive predictive value, negative predictive value, and accuracy) of six different tests to detect and diagnose CTS

\begin{tabular}{|c|c|c|c|c|c|c|c|}
\hline \multicolumn{8}{|c|}{ Final diagnosis of CTS } \\
\hline Test & Positive group & Negative group & Sensitivity (\%) & Specificity (\%) & PPV (\%) & NPV (\%) & Accuracy (\%) \\
\hline \multicolumn{8}{|l|}{ Duran's test } \\
\hline Positive & 258 & 19 & 86 & 93.7 & 93 & 87 & 89 \\
\hline Negative & 42 & 281 & & & & & \\
\hline \multicolumn{8}{|c|}{ Modified Duran's test } \\
\hline Positive & 282 & 18 & 94 & 94 & 94 & 94 & 94 \\
\hline Negative & 18 & 94 & & & & & \\
\hline \multicolumn{8}{|c|}{ Phalen's test } \\
\hline Positive & 236 & 48 & 78.7 & 84 & 90.8 & 88.7 & 81.3 \\
\hline Negative & 64 & 252 & & & & & \\
\hline \multicolumn{8}{|c|}{ Revered Phalen's test } \\
\hline Positive & 225 & 53 & 75 & 82 & 80.9 & 76.7 & 78.7 \\
\hline Negative & 75 & 247 & & & & & \\
\hline \multicolumn{8}{|l|}{ Tinel's test } \\
\hline Positive & 209 & 36 & 69.7 & 88 & 85.3 & 70.1 & 76 \\
\hline Negative & 91 & 264 & & & & & \\
\hline \multicolumn{8}{|c|}{ Tourniquet test } \\
\hline Positive & 159 & 69 & 53 & 77 & 69.7 & 62.1 & 65 \\
\hline Negative & 141 & 231 & & & & & \\
\hline
\end{tabular}

CTS: Carpal tunnel syndrome

Table 3: Positivity rate (sensitivity) of the different tests about the duration of the symptoms

\begin{tabular}{|c|c|c|c|c|c|c|c|c|c|c|c|c|}
\hline \multirow[t]{2}{*}{$\begin{array}{l}\text { Duration of symptoms } \\
\text { in months }\end{array}$} & \multicolumn{2}{|c|}{ Duran's test } & \multicolumn{2}{|c|}{$\begin{array}{c}\text { Modified } \\
\text { Duran's test }\end{array}$} & \multicolumn{2}{|c|}{ Phalen's test } & \multicolumn{2}{|c|}{$\begin{array}{c}\text { Revered } \\
\text { Phalen's test }\end{array}$} & \multicolumn{2}{|c|}{$\begin{array}{c}\text { Tinel's } \\
\text { test }\end{array}$} & \multicolumn{2}{|c|}{$\begin{array}{c}\text { Tourniquet } \\
\text { test }\end{array}$} \\
\hline & $n$ & $\%$ & $n$ & $\%$ & $n$ & $\%$ & $n$ & $\%$ & $n$ & $\%$ & $n$ & $\%$ \\
\hline$<1(n=22)$ & 13 & 59.1 & 18 & 81.8 & 10 & 45.4 & 10 & 45.4 & 13 & 59.1 & 15 & 68.2 \\
\hline $1-3$ months $(n=84)$ & 63 & 75.0 & 76 & 90.4 & 51 & 60.7 & 50 & 59.5 & 43 & 51.2 & 30 & 35.7 \\
\hline $4-5$ months $(n=126)$ & 118 & 93.7 & 124 & 98.4 & 113 & 89.7 & 103 & 81.7 & 98 & 77.8 & 70 & 55.5 \\
\hline More than 6 month $(n=68)$ & 64 & 94.11 & 64 & 94.1 & 62 & 91.1 & 62 & 91.2 & 55 & 80.9 & 44 & 64.7 \\
\hline$P$ (t-test) & \multicolumn{2}{|c|}{0.02} & \multicolumn{2}{|c|}{$<0.001$} & \multicolumn{2}{|c|}{$<0.001$} & \multicolumn{2}{|c|}{$<0.001$} & \multicolumn{2}{|c|}{0.003} & \multicolumn{2}{|c|}{$0.06(\mathrm{NS})$} \\
\hline
\end{tabular}

\section{DISCUSSION}

Provocative tests are broadly required for confirmation of the diagnosis, treatment selection, and determination of the cause and etiology of CTS. Although electrodiagnostic studies are considered to be the gold standard (abnormal test result is an objective prove of CTS) (Szabo et al., 1999; Gellman et al., 1986).

However, a positive result cannot confirm the diagnosis of CTS when there are no symptoms (Szabo et al., 1999).
Some patients with characteristic CTS signs may be qualified as candidates for surgical intervention and thus avoid costs and time associated with electrodiagnostic study (Durkan, 1991). The fact that clinical tests are an available and easy-to-use diagnostic method constitutes their greatest advantage (Szabo et al., 1999). The majority of authors agree that a positive result of high sensitivity and specificity provocative tests is an indication for further studies verifying the diagnosis, while a negative result does not exclude CTS (Bozek and Gaździk, 2001). Tests with high sensitivity should be used to differentiate patients with 
symptoms similar to CTS, while tests with high specificity can serve to eliminate falsely positive results and are thus especially useful in cases when surgical intervention is considered (Szabo et al., 1999; MacDermid and Wessel, 2004).

This study shows that $90 \%$ of cases were females while only $10 \%$ of cases were males which indicate that the female to male ratio is equal to 9:1 which is similar to the result of (Susan Ferry and Mariawarasky, 2000) This female predominance could be explained by the hormonal effect (Susan Ferry and Mariawarasky, 2000).

In this study, a combination of the test was used to diagnosis of CTS and confirmed by positive NCS, these hand the sensitivity of modified Duran's test was (94\%), and the specificity was (94\%), for CTS diagnosis with 18 hands false positive. While the sensitivity original Duran's test was (86\%), and specificity was (93.7). with 19 hands false-positive. The result is close enough to the result of (Al-Mukhtar, 2004). The sensitivity modified Duran's test was 94.7\% and specificity (94.7) (Al-Mukhtar, 2004).

From our study, we conclude that the modified Duran's test is a better diagnostic test than the other tests in the diagnosis of CTS due to more sensitivity and specificity than the other tests.

In modified Duran's test, the applied pressure was sustained and precise (stoppage valve) by a firm device (the physical advantage of the firm substance allows a better pressure transmission than a soft one, this was utilized in designing the modified Duran's device) on the median nerve running under the flexor retinaculum to induce transient reversible ischemia and direct pressure nerve conduction block in short duration using the mercurial sphygmomanometer which is documented to be more precise and accurate than aneroid type (Andrews, 1972).

While in the original Duran's test, the applied pressure was through a soft rubber atomizing bulb, which is difficult to maintain the standard pressure for the appropriate time because there is no Valve to stop the pressure on the recommended level.

There have been few published studies on the highest specificity and sensitivity of the original Duran's test as compared to other provocative tests in the diagnosis of CTS, as follows

There have been few published studies on the highest specificity and sensitivity of the original Duran's test as compared to other provocative tests in the diagnosis of carpal tunnel syndrome, as follows: Kuschner SH
(Kuschner, 1999) duran's test sensitivity was (89\%) and specificity (93\%), while Phalen test sensitivity was $83 \%$ and specificity $82 \%$. Richter M (Rickter M, 1999) duran's test sensitivity was $(87 \%$ ) and specificity $96 \%$ while Phalen test sensitivity was (64\%) and specificity (87\%). Joh Duran (Durkan, 1991) duran's test sensitivity was (87\%) and sensitivity (90\%). While Phalen test sensitivity was (70\%) and sensitivity (84\%).

The sample size of this study considered as largest if compared to other published researches such as (Durkan, 1991), (Williams et al., 1992), (Tetro et al., 1998), (Al-Mukhtar, 2004) which adds to the accuracy of these studied tests.

\section{CONCLUSION}

To make a test useful for diagnosing a disease, it should be highly sensitive and specific for the disease being studied.

1. Modified Duran's test was the most sensitive (94\%) and most specific (94\%), with the highest positive predictive value and negative predictive value compared to other clinical tests

2. It is the most helpful test for diagnosis and screening of CTS in patients with a typical history

3. It is a very helpful simple, noninvasive, and inexpensive test

4. Test to pare form in the painful wrist or stiffness wrist

5. Modified Duran's test was found to have the least reaction time to be positive and it can detect early cases of CTS.

\section{REFERENCES}

Al-Mukhtar, A. W. 2004. Evaluation of clinical tests in diagnosis of carpal tunnel syndrome with special reference to modified Duran's test regarding specificity and sensitivity. Basrah J. Surg. 10: 78-86.

Andrews, B. 1972. Experiment of Physiology. Chirchill Livingstone, London.

Boland, R. A. and R. D. Adams. 1999. Sphygmomanometer-induced increases in forearm and hand volume. J. Hand Ther. 12: 275283.

Bozek, M. and T. S. Gaździk. 2001. The value of clinical examination in the diagnosis of carpal tunnel syndrome. Ortop. Traumatol. Rehabil. 3(3): 357-360.

De-La-Llave-Rincón, A. I., E. J. Puentedura and C. FernándezDe-Las-Peñas. 2012. New advances in the mechanisms and etiology of carpal tunnel syndrome. Discov. Med. 13: 343-348.

Douglas, G., Tompkins MD., Larosse, et al. Median nerve neuropathy in the CTS caused by tumor like condition. $\mathrm{J}$ Bone and Joint Surg 1981;21:373-83.

Durkan, J. A. 1991. A new diagnostic test for carpal tunnel syndrome. J. Bone Joint Surg. Am. 73: 535-538.

Gellman, H., R. H. Gelberman, A. M. Tan and M. J. Botte. 1986. Carpal 
tunnel syndrome. An evaluation of the provocative diagnostic tests. J. Bone Joint Surg. Am. 68: 735-737.

Kang, S., H. K. Kwon, K. H. Kim and H. S. Yun. 2012. Ultrasonography of median nerve and electrophysiologic severity in carpal tunnel syndrome. Ann. Rehabil. Med. 36: 72-79.

Kuschner, S. H. 1999. Reliability and validity of physical examination tests used to examine the upper extremity. J. Hand Surg. Am. 24: 868-869.

Louis, D. S. and F. M. Hankin. 1987. Symptomatic relief following carpal tunnel decompression with normal electroneuromyographic studies. Orthopedics. 10: 434-436.

Macdermid, J. C. and J. Wessel. 2004. Clinical diagnosis of carpal tunnel syndrome: A systematic review. J. Hand Ther. 17: 309319.

Parisdm, T. T. 2005. Wrist and hand reconstruction. In: AAOS Orthopaedic Knowledge Update 8.

Phalen, G. S. 1972. The carpal-tunnel syndrome. Clinical evaluation of 598 hands. Clin. Orthop. Relat. Res. 83: 29-40.

Rahmani, M.,A. R. Ghasemi Esfe, S. M. Vaziri-Bozorg, M. Mazloumi, O. Khalilzadeh and H. Kahnouji. 2011. The ultrasonographic correlates of carpal tunnel syndrome in patients with normal electrodiagnostic tests. Radiol. Med. 116: 489-496.

Rickter, M. and P. Brüser. 1999. The value of clinical diagnosis in CTS. Handchir. Mikrochir. Plast. Chir. 31: 373-377.
Sorlie, D. E. 1995. Medical Biostatistics and Epidemiology: Examination and Board Review. Appleton and Lange, Norwalk, Connecticut.

Susan Ferry, P. H. and M. Warasky. 2000. CTs risk factors in women. AJE. 151(6): 566-573.

Szabo, R. M., R. R. Jr. Slater, T. B. Farver, D. B. Stanton and W. K. Sharman. 1999. The value of diagnostic testing in carpal tunnel syndrome. J Hand Surg. Am. 24: 704-714.

Tetro, A. M., B. A. Evanoff, S. B. Hollstien and R. H. Gelberman. 1998. A new provocative test for carpal tunnel syndrome. Assessment of wrist flexion and nerve compression. J. Bone Joint Surg. Br. 80(3): 493-498.

Trumble, T. E., E. Diao, R. A. Abrams and M. M. Gilbert-Anderson. 2002. Single-portal endoscopic carpal tunnel release compared with open release: A prospective, randomized trial. J. Bone Joint Surg. Am. 84: 1107-1115.

Wanitwattanarumlug, B. and V. Varavithya. 2012. Evaluating the mean cross-sectional area (CSA) of median nerve by use of ultrasound in Thai population. J. Med. Assoc. Thai. 95: 21-5.

Werner, R. A. and M. Andary. 2011. Electrodiagnostic evaluation of carpal tunnel syndrome. Muscle Nerve. 44: 597-607.

Williams, T. M., S. E. Mackinnon, C. B. Novak, S. McCabe and L. Kelly. 1992. Verification of the pressure provocative test in carpal tunnel syndrome. Ann. Plast. Surg. 29(1): 8-11. 